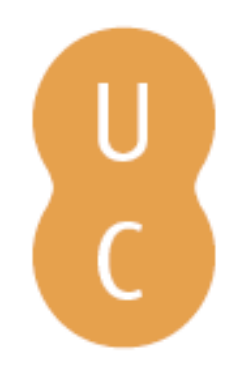

\title{
pommalina
}

\section{[Recensão a] Bioética y hermenéutica. La ética deliberativa de Paul Ricoeur}

\author{
Autor(es): $\quad$ Alonso Fernández, Marcos \\ Publicado por: Imprensa da Universidade de Coimbra \\ URL \\ persistente: URI:http://hdl.handle.net/10316.2/43639 \\ DOI: $\quad$ DOl:https://doi.org/10.14195/978-989-26-1516-5_9
}

Accessed : $\quad$ 26-Apr-2023 10:37:24

A navegação consulta e descarregamento dos títulos inseridos nas Bibliotecas Digitais UC Digitalis, UC Pombalina e UC Impactum, pressupõem a aceitação plena e sem reservas dos Termos e Condições de Uso destas Bibliotecas Digitais, disponíveis em https://digitalis.uc.pt/pt-pt/termos.

Conforme exposto nos referidos Termos e Condições de Uso, o descarregamento de títulos de acesso restrito requer uma licença válida de autorização devendo o utilizador aceder ao(s) documento(s) a partir de um endereço de IP da instituição detentora da supramencionada licença.

Ao utilizador é apenas permitido o descarregamento para uso pessoal, pelo que o emprego do(s) título(s) descarregado(s) para outro fim, designadamente comercial, carece de autorização do respetivo autor ou editor da obra.

Na medida em que todas as obras da UC Digitalis se encontram protegidas pelo Código do Direito de Autor e Direitos Conexos e demais legislação aplicável, toda a cópia, parcial ou total, deste documento, nos casos em que é legalmente admitida, deverá conter ou fazer-se acompanhar por este aviso.

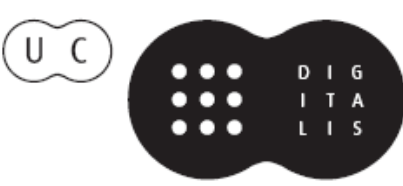


善商

Gonçalo Marcelo

César Correa Arias

Patrícia Lavelle

\#1

Tomás Domingo Moratalla COORDS.

A Atualidade

de Paul Ricour

numa Perspetiva

Ibero-Americana

Imprensa da Universidade de Coimbra

Coimbra University Press 
A Ricœuriana é uma série de livros (abrangendo monografias e volumes coletivos) disponibilizados em acesso aberto, dedicada à obra de Paul Ricœur e aberta a contribuições que também versem sobre outros autores e áreas, fomentando um permanente espírito de diálogo e interdisciplinaridade. As suas publicações abrangem diversos domínios da filosofia (estética, ética, fenomenologia, filosofia social e política, hermenêutica), mas também de disciplinas como os estudos literários, a história, a psicanálise, e a teologia, entre outras áreas relevantes para o pensamento de Ricœur. 
Reseña (Book Review) de Tomás Domingo Moratalla, Agustín Domingo Moratalla (ed.), Bioética y hermenéutica. La ética deliberativa de Paul Ricœur (Actas del Congreso Internacional, Valencia, España, febrero 2013), Editorial Hermes, Valencia, 2014, pp. 429 (libro electrónico-Amazon) ISBN: 978-84-96657-33-5

Marcos Alonso Fernández ${ }^{1}$

Una vida y obra como la de Paul Ricour (1913-2005) bien merece ser recordada. Pocos filósofos a lo largo de la historia han asumido con mayor fidelidad y entrega la tarea del pensamiento, y a estos grandes ejemplos debemos volver una y otra vez para aprender y re-aprender qué es realmente la filosofía. Con motivo del centenario del nacimiento de Ricour apareció el presente trabajo, Bioética y hermenéutica. La ética deliberativa de Paul Ricour, editado por Tomás Domingo Moratalla y Agustín Domingo Moratalla.

En esta obra podemos observar tres vertientes bien diferenciadas, si bien estrechamente comunicadas y en perpetua convergencia: la aportación de Ricœur a la hermenéutica, su contribución al campo de la ética aplicada, y la relevancia de su obra para la bioética. En torno a estas tres líneas y sus entrecruzamientos giran todos los

${ }^{1}$ Marcos Alonso Fernández, Departamento de Filosofía del Derecho, Moral y Política II de la Universidad Complutense de Madrid, Ciudad Universitária, Plaza Menéndez Pelayo, s/n, 28040 Madrid, España. Mail: marcs.alonso@gmail.com 
trabajos compendiados en Bioética y hermenéutica. La ética deliberativa de Paul Ricour.

Entre los trabajos de la primera línea, dedicada a la hermenéutica, cabría destacar la clara introducción a esta base hermenéutica del pensamiento de Ricœur por parte de Marcelino Agís Villaverde en "Fundamentos hermenéuticos de la ética de Paul Ricœur". Encontramos interesantes reflexiones sobre la naturaleza de testimonio y confesión en "Du témoignage et de l'aveu", de Johann Michel, lo mismo que sobre la base bíblica de algunas concepciones éticas ricœurianas en "Palabra bíblica e autonomía ética en Paul Ricœur" de Michel Renaud. Dos sugerentes trabajos sobre la comprensión hermenéutica de la enfermedad son "Santé, médecine et maladie. Lecture comparative des écrits topiques de Paul Ricœur et de Georges Canguilhem" de Gilbert Vincent y "Expliquer, comprendre et vivre la maladie" de Jérôme Porée.

La segunda línea de aportaciones, centradas en el aspecto ético del pensamiento de Ricour, tiene también una fuerte representación en la obra. Un trabajo a destacar es, por supuesto, la aportación de Diego Gracia, quien examina los distintos niveles de la reflexión ética ricœuriana en "Supra-ética" y "pequeña ética" en Paul Ricœur. El trabajo "Sagesse pratique, soin et responsabilité: les ressources éthiques de la philosophie de Paul Ricœur" de Lazare Benaroyo es también una brillante aportación al libro. En este importante trabajo se presenta a la ética ricœuriana dentro de las llamadas éticas del cuidado, mostrando asimismo la productividad de las categorías de Ricœur en este campo. Una aproximación más fenomenológica y metafísica es la de Gonçalo Marcelo "A Ética como Exploração do Possível"; una línea en la cual también se inserta el trabajo de Daniella Iannota "Por une éthique de la vie heureuse: Paul Ricœur". En el intersticio entre ética y bioética encontramos el trabajo de César Correa Arias "Mi sufrimiento contado por otros. Los procesos de narración en salud desde una ética hermenéutica". Estos trabajos 
dan una muestra de las posibilidades de la ética ricœuriana, un terreno fértil que todavía puede dar mucho de sí.

Es precisamente la línea bioética la que acapara una mayor parte de trabajos. Encontramos en esta línea importantes trabajos como: "Ricour, the bioethics of happiness and related delusional states" de Alison Scott-Baumann, donde se apunta una reflexión sobre la felicidad y su importancia en el ámbito sanitario; "A humanidade do homem. Do neuronal à ética da deliberação" de Paula Ponce de Leão, trabajo en el que se pone en conexión la neurociencia con la ética de la deliberación ricœuriana; o "A importancia de P. Ricœur para o ámbito da decisäo em bioética: imaginação narrativa e sabedoria prática" de María Luisa Portocarrero, donde se reivindica con fuerza la vigencia y actualidad de Paul Ricœur en la reflexión bioética.

Esta rápida referencia a alguno de los estudios contenidos en Bioética y hermenéutica. La ética deliberativa de Paul Ricoeur puede darnos una buena idea de lo que esta obra nos ofrece. No obstante, comentaré con más detalle algunos artículos en los cuáles encontramos aspectos particularmente interesantes.

El trabajo que abre el libro es "Crítica y corazón: la ética narrativa de Paul Ricour", de Agustín Domingo Moratalla. El trabajo de A. Domingo, uno de los más completos e interesantes de la obra, se centra en exponer la ética narrativa de Ricour, justificando el adjetivo bajo la que se presenta dicha ética. A. Domingo explica cómo la filosofía de Ricœur estaba orientada desde un principio hacia la ética con sus trabajos sobre la voluntad, si bien esta ética implícita solo se volvió explícita cuando se abrió al diálogo con otros autores como Marcel o Jaspers. Es así como Ricœur acabará abanderando la "transformación narrativa de la fenomenología" en los años setenta y ochenta, sentando las bases para la que sería una fuerte tradición filosófica. En este sentido, los análisis ricœurianos de la narratividad son clave a la hora de llevar a cabo una ampliación - que no una anulación - de la racionalidad, que a su vez nos permite entender 
mejor a un sujeto que pasa a comprenderse como descentrado y necesariamente parte de un relato. La importancia de la identidad narrativa para la identidad moral no puede ser subestimada, según A. Domingo, pues es el único método que se acerca a dar verdadera cuenta de la complejidad inherente a los asuntos humanos. La ética de Ricœur, acabará diciendo A. Domingo, será por tanto una ética del reconocimiento, una ética de la responsabilidad, y, por tanto, una ética prudencial que recoge la indispensable categoría aristotélica de la phronesis.

Fernanda Henriques lleva a cabo un sugerente análisis titulado "La ficción narrativa de la identidad narrativa de Paul Ricœur", donde muestra cómo Ricœur pone de manifiesto la constitutiva fragilidad y vulnerabilidad humana, junto a sus consecuencias éticas. La identidad se basa en una compleja permanencia en el tiempo, del cual es ejemplo privilegiado el caso de la promesa. Este tiempo humano vendría a ser un entrecruzamiento del tiempo fenomenológico y tiempo cosmológico, que sin embargo nunca permite la construcción de una identidad cerrada y perfectamente acabada. F. Henriques reitera, como otros trabajos del libro, la importancia que estas averiguaciones narrativas tienen para nuestras consideraciones ético-prácticas, un punto que nos parece de especial importancia y cuya reivindicación es más necesaria hoy que nunca.

El trabajo de Patricio Mena, "La lucidez del cuidado", supone un interesantísimo ejercicio fenomenológico sobre el cuidado, tomando como punto de partida la filosofía de Ricœur. Partiendo del análisis ricouriano sobre la atención, P. Mena expone como el cuidado contiene en sí mismo categorías tan importantes como la apertura a lo inesperado, la responsividad y la responsabilidad. El cuidado es un acontecimiento que implica una apelación, y que, por tanto, nos pone en el camino de la escucha. Todo lo cual lleva implícita una crítica al sujeto trascendental husserliano, que desde filosofías como la de Ricœur aparece duramente criticado en sus pretensiones. 
Con la aportación de Lydia Feito Grande, "Ricœur 'en' los comités de bioética: la práctica de la deliberación. Interdisciplinaridad y metáfora deliberativa", nos encontramos con uno de los trabajos más jugosos y potentes del libro. L. Feito tratará el problema concreto de los comités de bioética, con comentarios e indicaciones provenientes de la propia experiencia y de la filosofía de Paul Ricœur. El interés del trabajo es, por tanto, doble: se trata un tema real y relevante, pero a la vez se ponen en uso y a prueba las categorías ricœurianas sobre bioética. L. Feito, tras un breve recorrido por la historia de la joven disciplina bioética, expone su preferencia por una idea de "integración en la complejidad", frente a la ambigua concepción de la interdisciplinariedad. Respecto del tema concreto de los comités de bioética, L. Feito empezará diciendo que los conflictos no son necesariamente negativos, por cuanto muchas veces son generadores de sentido. Precisamente, el método deliberativo defendido por Ricœur parte del reconocimiento de que no podemos aspirar a verdades absolutas, solo a aproximaciones prudenciales. Esto no debe hacernos caer en el relativismo; y para ello la única solución es una ida y venida continua desde el plano normativo al caso concreto. El consenso, desde esta perspectiva, no es el fin último, sino que está supeditado a la creación de sentido, donde la imaginación y la metáfora se erigen como categorías clave. La bioética, concluye L. Feito, pasa a ser así algo más que una mera ética profesional, pudiendo aplicarse algunas de sus categorías a la política o a la educación.

La reflexión de Juan Masiá, titulada "Reconocimiento y responsabilidad", es una bella mezcla de sucinta exposición de la ética de Ricœur y testimonio personal de su relación con el hombre que fue Ricœur. El reconocimiento, en este caso, deja de ser una categoría filosófica y pasa a ser algo que transpira de las palabras de J. Masiá, al recordar al que considera, sin lugar a dudas, como un maestro. El texto de J. Masiá se centra en la importancia que tuvo la lectura 
para Ricœur. Un leer, que siempre fue un interpretar, y que por tanto no fue solo un leer textos, sino un leer personas, tradiciones y vidas. Un leer complejo y trufado de puntos de vista, que siempre enriquecía lo leído. El autor destaca asimismo la persistente reivindicación ricœuriana de la sagesse pratique, la cual, en continuidad con Aristóteles, evitaba caer extremos y privilegiaba categorías como la deliberación y la responsabilidad.

En "Los niveles del juicio médico y las tareas de un Comité Nacional de Bioética" de Antonio da Re, podemos ver otro buen ejemplo de aplicación bioética de las categorías ricœurianas. A. da Re expone la distinción entre los tres niveles del juicio médico: prudencial, deontológico y reflexivo, relacionando cada uno de los niveles con un filósofo paradigmático de cada corriente: Aristóteles con el prudencial, Kant con el deontológico y, en menor medida, Rawls con el reflexivo. Vemos así las posibilidades internas del pensamiento ricouriana para el diálogo entre distintas tradiciones, un potencial de valor incalculable.

Otro trabajo fundamental de los compendiados en el libro es el de Tomás Domingo Moratalla. Bajo el título "El 'efecto Ricœur' en bioética. La pequeña bioética de Paul Ricœur (hacia una bioética hermenéutica)", T. Domingo nos invita a pensar una "pequeña bioética” al hilo de la "pequeña ética” defendida por Ricœur; al mismo tiempo que se aboga por una bioética hermenéutica en la que la unión de ambos términos no sea casual sino mutuamente reafirmante. El método de Ricour, nos dirá el autor, si por algo se caracteriza es por su complejidad, por optar siempre por la vía larga. La bioética ricouriana, como su ética, será deliberativa, responsable y estará basada en la constitución narrativa y frágil del ser humano. El efecto Ricœur, que da título al trabajo, se refiere precisamente a este enriquecimiento y ganancia en complejidad, siempre basado en el diálogo, que la hermenéutica ricœuriana ha supuesto para la bioética, y de la que todavía puede seguir aprovechándose. Como termina 
diciendo el autor, y con lo que estamos plenamente de acuerdo, el efecto Ricœur es un efecto beneficioso que además importa mucho que se deje notar, por cuanto con él se ponen en juego algunos de los problemas más acuciantes de nuestro mundo actual.

Bioética y hermenéutica. La ética deliberativa de Paul Ricour es, en definitiva, una obra que hace justicia a la vida y obra de Paul Ricœur, reivindicando el enorme valor de su pensamiento. Muestra de ello es la vigencia de Ricour para la bioética, una disciplina que ejemplifica de la mejor manera los valores filosóficos defendidos por Ricœur: la aproximación compleja y alejada de reduccionismos, la responsabilidad ante los problemas del presente, la voluntad de diálogo y la preponderancia de la preocupación práctica. De este modo, el presente libro alcanza su más alto fin: convertirse en una irresistible invitación a la lectura de la obra de Paul Ricœur.

Financiación: Marcos Alonso Fernández es Becario de la Fundación Oriol Urquijo. 